\title{
PENGELOLAAN KAWASAN PESISIR KABUPATEN BULELENG MELALUI PENGEMBANGAN MINA WISATA BAHARI (Management of Buleleng Coastal Areas Through the Marine Fisheries Tourism Development)
}

\author{
Gede Ari Yudasmara* \\ Jurusan Budidaya Kelautan, Fakultas Matematika dan Ilmu Pengetahuan Alam, \\ Universitas Pendidikan Ganesha, Jl. Udayana No. 11, Singaraja-Bali, 81116. \\ *Korespondensi: Tel: 082147662800. Email: ariyudasmara@gmail.com.
}

\author{
Diterima: 18 Desember 2015
}

Disetujui: 5 Agustus 2016

\begin{abstract}
Abstrak
Kawasan pesisir Kabupaten Buleleng saat ini telah dimanfaatkan dengan berbagai kegiatan kepariwisataan, akan tetapi kegiatan tersebut masih belum memberikan manfaat yang optimal bagi masyarakat dan memiliki kecenderungan mengalami kejenuhan. Untuk itu, diperlukan suatu pengembangan wisata alternatif yang sesuai dengan kondisi dan potensi sumber daya alam yang ada serta saling bersinergi dengan aktivitas wisata lainnya, seperti contohnya pengembangan mina wisata. Penelitian ini bertujuan untuk mengkaji dan menganalisis kondisi dan potensi sumberdaya alam pesisir dan laut, tingkat kesesuaian kawasan pesisir Buleleng dalam menunjang pengembangan mina wisata dan menghasilkan model aktivitas mina wisata di kawasan pesisir Buleleng yang terpadu dan berkelanjutan. Penelitian ini menggunakan pendekatan kesesuaian kawasan dengan rancangan penelitiannya berupa survei lapangan. Hasil penelitian menunjukkan bahwa pesisir Kabupaten Buleleng apabila dilihat dari kondisi dan potensi sumberdaya alamnya masih mampu untuk mendukung aktivitas mina wisata dengan tingkat kesesuaian kawasan berdasarkan indeks kesesuaian wisata, yaitu pesisir Buleleng timur terkategori cukup sesuai (76,92), pesisir Buleleng tengah terkategori cukup sesuai $(61,53)$ dan pesisir Buleleng barat terkategori sangat sesuai $(87,17)$. Rencana model mina wisata yang dapat dikembangkan antara lain pesisir Buleleng timur adalah mina wisata budidaya laut (ikan hias dan karang) dan mina wisata perikanan tangkap (pemancingan dan spearfishing adventures), pesisir Buleleng tengah adalah mina wisata budidaya laut (rumput laut) dan mina wisata perikanan tangkap (pemancingan dan spearfishing adventures), dan pesisir Buleleng barat adalah mina wisata budidaya laut (rumput laut, Bandeng, Kerapu, Mutiara, ikan hias dan karang) dan mina wisata perikanan tangkap (pemancingan dan spearfishing adventures).
\end{abstract}

Kata kunci: kawasan pesisir Buleleng, mina wisata, wisata bahari, pengelolaan, tingkat kesesuaian.

\begin{abstract}
Buleleng coastal area has been used for various tourism activities, however, the activities have not given an optimum benefit for the community and tend to experience saturation. This study was aimed at investigating the condition and potentiality of the coastal area and the sea, the degree of fit of Buleleng coastal area in supporting the development of fisheries tourism and at producing a model of the coastal area tourism activities that are integrated and sustainable. This study used the approach of area suitability with field survey design. The results showed that Buleleng regency coastal area, viewed from the point of the condition and the potentiality of the natural resources still has the capacity to support fisheries tourism. The model plannings of fisheries tourisms that can be developed, among others, are: the East Buleleng coastal area (76.92) is suitable for marine culture fisheries tourism (ornamental fish and coral) and fished fisheries tourism (fishing and spearfishing adventures); the central Buleleng coastal area (61.53) for marine culture fisheries tourism (seaweed) and fished fisheries tourism (fishing and spearfishing adventures), and the West Buleleng coastal area (87.17) for marine culture fisheries tourism (seaweed, milk fish, grouper, pearl, ornamental fish and coral) and fished fisheries tourism (fishing and spearfishing adventures).
\end{abstract}

Keywords: Buleleng coastal area, fisheries tourism, level of conformity, management, marine tourism.

\section{PENDAHULUAN}

Kabupaten Buleleng yang secara geografis terletak di bagian utara Pulau Bali memiliki potensi kelautan cukup tinggi. Hal ini terkait dengan panjang pantai hingga mencapai 157,05 km (Anonim, 2013). Kondisi ini tentunya memberikan peluang bagi berbagai usaha pemanfaatan termasuk di dalamnya pengembangan dan peningkatan sektor kepariwisataan. Kendatipun kabupaten ini telah mengembangkan kegiatan kepariwisataan, terutama wisata bahari, namun kegiatan tersebut masih belum memberikan manfaat yang optimal bagi masyarakat dan memiliki kecenderungan mengalami kejenuhan. Saat ini aktivitas wisata bahari di Kabupaten Buleleng masih mengandalkan wisata selam 
(diving), snorkeling, dan dolphin watching pada beberapa tempat wisata seperti kawasan Lovina, Batu Ampar, Sambirenteng dan Pulau Menjangan. Di sisi lain kualitas sumberdaya dan lingkungan di beberapa tempat wisata juga mengalami penurunan. Sebagai contoh di tahun 2010, penurunan atau kerusakan kondisi ekosistem terumbu karang pada kawasan Pulau Menjangan telah mencapai hingga 46 $\%$ (Yudasmara, 2010). Penurunan ini juga diikuti oleh penurunan jumlah kunjungan wisatawan ke Pulau Menjangan dari tahun 2001 sebesar 21.660 orang menjadi 13.970 orang di tahun 2011 (Yudasmara, 2013).

Kondisi tersebut menggambarkan aktivitas wisata bahari di Kabupaten Buleleng perlu dibenahi dan dikembangkan lagi, tidak hanya dengan atraksi wisata yang sudah ada tetapi juga mengembangkan aktivitas wisata alternatif lainnya yang sesuai dengan kondisi dan potensi sumber daya alam yang ada serta saling bersinergi dengan aktivitas wisata yang sudah lebih dahulu ada, seperti contohnya pengembangan mina wisata bahari. Mina wisata adalah pemanfaatan kawasan wisata dengan pengembangan produksi perikanan untuk mencapai ketertarikan masyarakat pengguna akan pengembangan perikanan pada kawasan wisata tersebut (Darmawan dan Miftahul, 2012). Dengan kata lain, mina wisata adalah pengembangan kegiatan perekonomian masyarakat dan wilayah yang berbasis pada pemanfaatan potensi sumberdaya kelautan, perikanan dan pariwisata secara terintegrasi pada suatu wilayah tertentu (Kasnir, 2011). Erlend dkk. (2011), Volstad dkk. (2011), Strehlow dkk. (2012) dan Ferter dkk. (2013) menyebutkan bahwa pengembangan wisata perikanan dapat meningkatkan keuntungan ekonomi dalam skala lokal dengan beberapa skenario pengelolaan di dalamnya. Oleh karena itu, peneliti memandang perlu segera dihasilkan suatu alternatif pengembangan dan pengelolaan wisata bahari yang secara terintegrasi melibatkan seluruh komponen ekologi/lingkungan, ekonomi dan sosial masyarakat melalui sebuah model mina wisata bahari terpadu dan berkelanjutan dengan harapan model ini mampu meningkatkan daya saing masyarakat Buleleng-Bali. Untuk itu, perlu dikaji dan dianalisis kondisi dan potensi sumberdaya alam pesisir-laut, aktivitas ekonomi wisata bahari, kondisi sosial budaya masyarakat lokal, dan tingkat kesesuaian kawasan pesisir Buleleng dalam menunjang aktivitas Mina wisata bahari serta untuk menemukan dan menghasilkan model pengembangan dan pengelolaan Mina wisata bahari yang tepat dan optimal secara ekologi, ekonomi dan sosial dalam menjamin keberlangsungan sumber daya alam dan kehidupan sosial ekonomi masyarakat setempat.

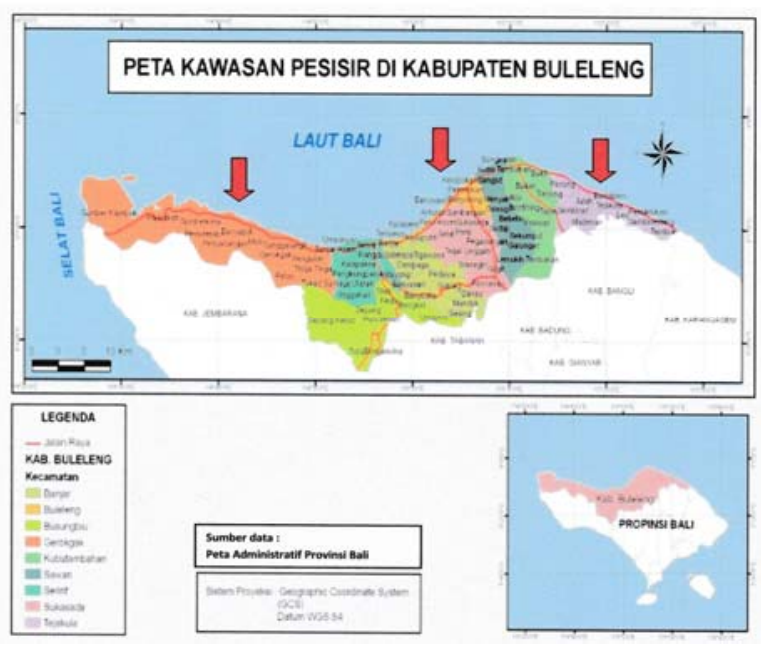

Gambar 1. Lokasi penelitian.

\section{METODE PENELITIAN}

\section{Waktu dan Lokasi}

Penelitian ini dilaksanakan dari bulan April sampai Agustus 2014 dengan lokasi penelitian sepanjang pesisir Kabupaten Buleleng-Bali Utara yang terbagi dalam 3 (tiga) stasiun pengamatan, yaitu: pesisir Buleleng Timur, Tengah, dan Barat (Gambar 1). Secara spesifik pengambilan sampel di ketiga stasiun tersebut mempertimbangkan kawasan yang sudah ada aktivitas wisatanya, dengan maksud agar mudah diperkenalkan kepada para wisatawan yang datang berkunjung ke kawasan tersebut.

\section{Prosedur Penelitian}

Penelitian ini menggunakan rancangan berupa survei lapangan. Untuk pengamatan kondisi karang menggunakan metode Manta Tow dan Line Intercept Transect (LIT) mengikuti English dkk. (1994), pengamatan ikan menggunakan Underwater fish Visual Census (UVC), pengamatan kualitas air menggunakan alat water quality checker (merk Horiba), dan pengamatan sosial ekonomi masyarakat melalui wawancara langsung dan penyebaran kuesioner.

\section{Analisis Data}

Data yang diperoleh, dianalisis secara deskriptif kualitatif dan kuantitatif tanpa menggunakan analisis statistika. Untuk penutupan karang, dihitung dengan rumus tutupan karang hidup menurut English dkk. (1994), yaitu :

Penutupan karang $=\frac{\text { Panjang kategori life form ke-i }}{\text { Total panjang transek }} \times$
$100 \%$

Bachtiar (2001) menyatakan bahwa persentase penutupan terumbu karang dapat dibagi menjadi lima kategori, yaitu sangat jelek : 0 - $10 \%$, jelek : 11 
- $30 \%$, sedang : $31-50 \%$, baik : $51-75 \%$ dan sangat baik : $76-100 \%$.

Untuk menganalisis kesesuaian lahan ini mengacu pada Hutabarat dkk (2009), adalah sebagai berikut:

$\mathrm{IKW}=\left[\sum \frac{\mathrm{Ni}}{\mathrm{N} \mathrm{mak}}\right] \times 100$

Tabel 1. Matriks kesesuaian lahan.

\begin{tabular}{|c|c|c|c|c|}
\hline No & Parameter & Bobot & $\begin{array}{c}\text { Standar } \\
\text { Parameter }\end{array}$ & Skor \\
\hline \multirow[t]{4}{*}{1} & Tutupan & 3 & $>75$ & 3 \\
\hline & karang & & $>50-75$ & 2 \\
\hline & hidup (\%) & & $25-50$ & 1 \\
\hline & & & $<25$ & 0 \\
\hline \multirow[t]{4}{*}{2} & Kecerahan & 3 & 100 & 3 \\
\hline & perairan & & $80-<100$ & 2 \\
\hline & $(\%)$ & & $20-<50$ & 1 \\
\hline & & & $<20$ & 0 \\
\hline \multirow[t]{4}{*}{3} & Jumlah & 2 & $>12$ & 3 \\
\hline & jenis & & $<7-12$ & 2 \\
\hline & form & & $4-7$ & 1 \\
\hline & & & $<4$ & 0 \\
\hline \multirow[t]{4}{*}{4} & Jumlah & 2 & $>100$ & 3 \\
\hline & jenis ikan & & $50-100$ & 2 \\
\hline & karang & & $20-<50$ & 1 \\
\hline & & & $<20$ & 0 \\
\hline \multirow[t]{5}{*}{5} & Kedalaman & 2 & $6-15$ & 3 \\
\hline & terumbu & & $>15-20$ & 2 \\
\hline & karang (m) & & atau $3-5$ & 1 \\
\hline & & & $>20-30$ & 0 \\
\hline & & & $\begin{array}{c}>30 \text { atau }< \\
3\end{array}$ & \\
\hline \multirow[t]{4}{*}{6} & Kecepatan & 1 & $0-15$ & 3 \\
\hline & arus & & $>15-30$ & 2 \\
\hline & (cm/det) & & $>30-50$ & 1 \\
\hline & & & $>50$ & 0 \\
\hline
\end{tabular}

Sumber: Davis dan Tisdell (1995); Davis dan Tisdell (1996); deVantier dan Turak (2004); Hutabarat dkk. (2009); Simon dkk. (2004).

Keterangan:

Nilai maksimum $=39$

$\mathrm{S} 1$ = Sangat sesuai, dengan nilai IKW $80-100$

$\mathrm{S} 3=$ Sesuai bersyarat, dengan nilai IKW $45-<60$

$\mathrm{S} 2=$ Cukup sesuai, dengan nilai IKW $60-<80$

S4 = Tidak sesuai, dengan nilai IKW $<45$

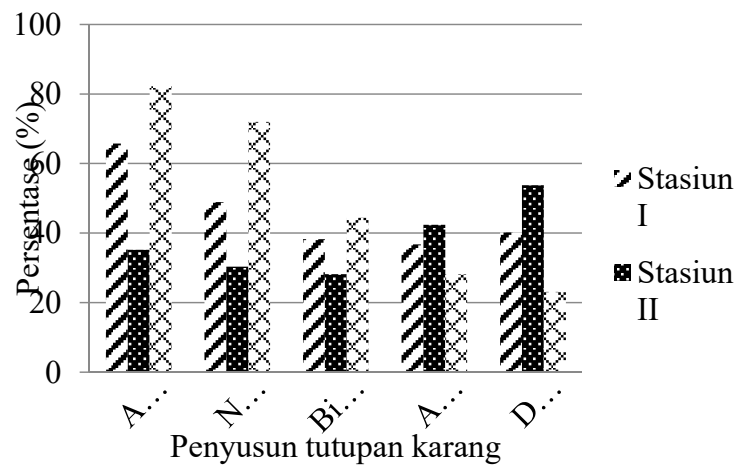

(a) (b) di mana :

IKW = indeks kesesuaian wisata

$\mathrm{N}_{\mathrm{i}} \quad=$ nilai parameter ke-i (bobot $\mathrm{x}$ skor)

$\mathrm{N}_{\text {mak }}=$ nilai maksimum

Pada tabel 1 disajikan matriks kesesuaian lahan yang digunakan untuk skoring pada penelitian ini.

\section{HASIL DAN PEMBAHASAN}

\section{Kondisi dan Potensi Sumber Daya Kawasan Pesisir Buleleng \\ Ekosistem terumbu karang}

Terumbu karang sebagai salah satu sumber daya alam di kawasan pesisir Buleleng memiliki gugusan karang yang sangat khas. Berdasarkan hasil pengamatan pada 3 stasiun pengamatan (pesisir Buleleng timur, pesisir Buleleng tengah dan pesisir Buleleng barat), memiliki kontur karang yang beranekaragam dari kontur yang datar sampai ke kontur yang tiba-tiba berubah drastis menjadi terjal atau dalam istilah selam disebut "drop off".

Pesisir Buleleng secara keseluruhan hampir merata dikelilingi oleh terumbu karang dari jenis karang tepi. Gambaran persentase tutupan karang di pesisir Buleleng disajikan pada Gambar 2.

Lokasi titik pengamatan pertama berada di pesisir Buleleng bagian timur, yaitu sekitar kecamatan Tejakula pada kedalaman 3 dan 10 meter, terdapat hamparan pasir hitam yang luas. Hasil yang didapatkan dengan menggunakan metode LIT, bahwa persentase tutupan karang hidup pada kedalaman 3 meter sebesar 49,35\% jenis acropora, non acropora $36,68 \%$, biota lain $28,73 \%$, dead coral 30,15 \% dan abiotik 27,60 \%. Untuk persentase tutupan karang hidup pada kedalaman 10 meter sebesar 16,45\% untuk jenis acropora, non acropora sebesar $12,23 \%$, biota lain 9,58 \%, dead coral $10,05 \%$ dan abiotik $9,20 \%$.

Jenis acropora yang ditemukan didominasi oleh acropora branching, acropora digitate, dan acropora tabulate sedangkan non acropora didominasi oleh coral foliose, coral branching, dan

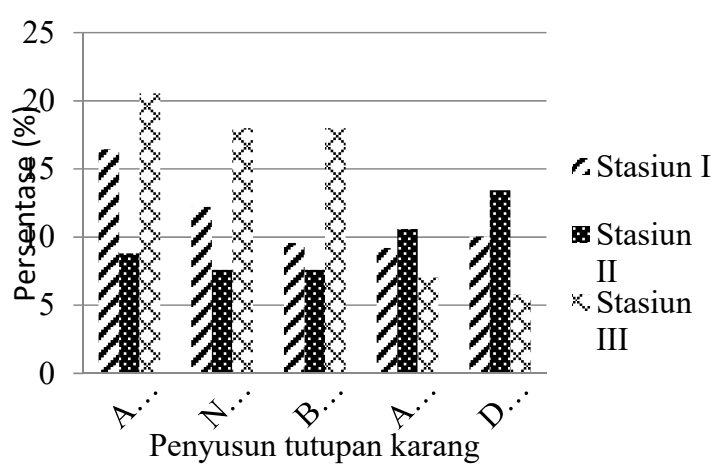

Gambar 2. Persentase tutupan karang pada kedalaman (a) 3 dan (b) 10 meter. 
coral massive. Selain itu, dijumpai pula biota lainnya seperti soft coral dan zooxanthid serta karang mati. Komponen abiotik terdiri dari pasir dan rubble (pecahan karang).

Pada stasiun pengamatan I ini profil rataan terumbu dengan kedalaman kurang dari 3 meter banyak diisi oleh hamparan pasir dan karang mati, namun semakin jauh dari pantai semakin banyak karang yang hidup dengan kedalaman lebih dari 3 meter atau berada pada tubir karang. Begitu pula pada kedalaman 10 meter banyak ditemukan patahan-patahan karang, kondisi ini diakibatkan sebelumnya telah terkena hama Acanthaster plancii dan terjadi bleaching. Kondisi ini juga diakibatkan oleh pelemparan/penambatan jangkar dan aktivitas pariwisata yang tidak bersahabat.

Penyelaman dan snorkeling yang ceroboh berpotensi dalam memindahkan patahan karang maupun menambah terjadinya patahan karang tersebut. Morfologi tubir dengan derajat kemiringan yang cukup tinggi, menyebabkan jatuhnya patahan karang ke kedalaman di bawahnya, sehingga berpotensi menimbulkan kerusakan fisik berantai. Secara umum dapat dikatakan bahwa tutupan karang hidup di stasiun I memiliki kondisi sedang, yaitu sebesar $57,35 \%$.

Stasiun kedua berada di pesisir Buleleng bagian tengah, yaitu berada didekat pemukiman penduduk. Transek diambil pada kedalaman 3 meter dan 10 meter. Persentase tutupan karang hidup pada kedalaman 3 meter adalah sebesar $26,44 \%$ dari jenis acropora dan non acropora sebesar $22,80 \%$. Selain itu, ditemukan juga biota lain seperti soft coral dengan persentase tutupan sebesar $21,15 \%$ serta komponen abiotik yang sedikit berupa substrat pasir dan rubble sebesar 31,80 \%.

Pada lokasi ini karang mati yang ditemukan berupa bongkahan karang mati dari jenis massive dengan persentase sebesar 40,31 \%. Persentase tutupan karang pada kedalaman sekitar 10 meter adalah sebesar $8,81 \%$ yang didominasi oleh jenis acropora dan jenis non acropora hanya 7,60 \%. Pada lokasi ini juga dijumpai juga biota lain seperti soft coral dengan persentase tutupan sebesar 7,05\%, komponen abiotik yang sedikit berupa substrat pasir dan rubble sebesar 10,60\% serta persentase tutupan karang mati sebesar $13,44 \%$.

Secara keseluruhan kondisi terumbu karang di stasiun II ini tergolong dalam kategori cukup, yaitu $32,83 \%$ dari kedua kedalaman yang diteliti. Kondisi ini dapat disebabkan karena pada stasiun II banyak terdapat pemukiman penduduk, hotel, gedunggedung, dan beberapa muara air sungai. Kondisi inilah yang mengakibatkan pada stasiun II ini tutupan karang hidupnya rendah. Terumbu karang akan sulit hidup dan berkembang apabila di lingkungan perairannya tidak mendukung untuk hidupnya, jumlah muara sungai dan belum lagi jumlah aktivitas masyarakat di lingkungan pesisir, sehingga memberikan tekanan yang berat bagi karang untuk hidup dan bertahan.

Stasiun ketiga berada di pesisir Buleleng bagian barat, yaitu berada di kecamatan Gerokgak sampai ke kawasan Pesisir Buleleng. Semakin ke arah barat hamparan pasirnya akan semakin berubah dari hitam menjadi putih begitu juga dengan vegetasi pohonnya akan lebih banyak menemukan vegetasi mangrove daripada vegetasi pohon lainnya, seperti kelapa, waru, dan pandan.

Pengukuran transek pada kedalaman 3 meter didapatkan persentase tutupan karang hidup sebesar $61,69 \%$ dengan jenis karang berupa acropora dan $54,01 \%$ berupa non acropora. Persentase tutupan untuk biota lain sebesar 33,35\%, sedangkan komponen abiotik yang terdiri dari substrat pasir dan rubble sebesar $21,12 \%$ serta persentase tutupan karang mati sebesar $17,34 \%$. Untuk pengukuran transek pada kedalaman 10 meter didapatkan hasil berupa acropora $20,56 \%$ dan non acropora $18,00 \%$, sedangkan $11,12 \%$ adalah biota lain seperti soft coral. Komponen lain seperti substrat pasir dan rubble sekitar 7,04\% dan tutupan karang mati sebesar 5,78\%.

Kondisi terumbu karang di stasiun ini tergolong dalam kategori baik yaitu $77,13 \%$. Kondisi lingkungan di lokasi ini memiliki gelombang dan arus yang cukup kuat, sehingga perlu perhatian yang lebih. Kondisi arus tersebut, memberikan pengaruh terhadap peningkatan jumlah karang lunak, gorgonian, sponge dan non acropora (coral foliose, coral massive, coral submassive, dan coral mushrom) pada rataan terumbu, tubir, dan dinding serta profil dindingnya yang hampir tegak lurus. Dexter dkk. (2014) dan Stone dkk. (2015) menyatakan bahwa arus perairan yang kuat akan membentuk corak habitat yang cukup beragam, sehingga keanekaragaman bentuk karang menjadi semakin tinggi.

Secara keseluruhan persentase tutupan karang hidup di pesisir Buleleng sebesar $55.77 \%$ atau dalam kategori baik. Menurut kriteria dari Hutabarat dkk. (2009), untuk aktivitas wisata bahari diperlukan syarat kondisi tutupan karang minimal sebesar $25 \%$ sampai lebih dari $75 \%$. Hasil perhitungan tersebut menunjukkan bahwa semua titik stasiun pengamatan dapat menunjang pengembangan kegiatan mina wisata bahari.

\section{Ikan karang}

Berdasarkan pengamatan pada tiga stasiun menunjukkan bahwa jenis ikan karang yang ditemukan pada umumnya berupa ikan hias dengan jumlah sekitar 52 jenis. Ikan tersebut kebanyakan membentuk schooling fish (kumpulan ikan) dengan 
warna dan bentuk yang beranekaragam. Keanekaragaman ikan hias tersebut terdiri dari: ikan target seperti famili Acanthuridae, famili Serranidae dan famili Labridae; ikan indikator dari famili Chaetodontidae dan ikan mayor seperti famili Pomacentridae, famili Scaridae, famili Pomacanthidae, famili Aulostomidae, famili Balistidae, famili Ephipidae, famili Holocentridae, famili Nemipteridae, famili Ostraciidae, famili Pinguipedidae, famili Tetraodontidae, dan famili Zanclidae.

Keberadaan ikan di area terumbu karang sangat bergantung pada kondisi terumbu karang itu sendiri. Seperti kelompok ikan indikator (ikan Kepe-Kepe; butterfly fish; famili Chaetodontidae) yang merupakan ikan indikator untuk menilai kesehatan terumbu karang memiliki kelimpahan yang cukup banyak. Begitu pula dengan kelompok ikan mayor, seperti Chromis analis, Chromis antripectoralis, Chromis caudalis dan Chromis margaritifer yang cukup banyak dijumpai kehadirannya hampir di setiap stasiun pengamatan.

Masih cukup banyak dijumpainya ikan indikator, yaitu dari famili Chaetodontidae, menandakan kondisi terumbu karang masih cukup baik. Menurut Nybakken (1993), ikan indikator merupakan ikan yang aktif memangsa koloni karang, seperti ikan Kepe-Kepe (Chaetodontidae), ikan Kakak Tua (Scaridae), ikan Pakal Tato (Balistidae), dan ikan Buntal (Tretaodontidae), Martinez dan Albenson (2013) serta Sammarco dkk (2014) menyebutkan bahwa kehadiran ikan Kepe-Kepe tidak terlepas dari keberadaan terumbu karang, karena ikan ini merupakan salah satu indikator kesehatan karang.

Semakin beragamnya spesies ikan dari kelompok ini menandakan tingkat kesehatan karang semakin tinggi. Keanekaragaman spesies ikan yang tinggi juga disebabkan oleh variasi habitat yang ada di ekosistem terumbu karang (Chateau dan Wantiez, 2009). Variasi habitat seperti daerah berpasir, berbagai lekuk dan celah, daerah alga, serta perairan yang dangkal atau dalam dapat menambah keragaman tidak hanya ikan tetapi juga biota laut lainnya, seperti berbagai jenis dari mega benthos.

\section{Potensi perikanan}

Kabupaten Buleleng merupakan salah satu kabupaten yang terletak dibagian utara Pulau Bali berbatasan dengan Laut Bali, sehingga sebagian besar wilayah kabupaten merupakan kawasan pesisir dengan panjang pantai $157,05 \mathrm{~km}$ dengan aneka ragam kekayaan laut yang potensial (luas laut 319,680 ha). Dari penduduk yang berjumlah sebanyak 786,972 pada tahun 2009 sebanyak 4.314 orang $(0,67 \%)$ bermata pencaharian sebagai nelayan, sedangkan yang bekerja sebagai petani ikan (pembudidaya) sebanyak 864 orang $(0,13 \%)$ (Anonim, 2013).

Perkembangan produksi di bidang perikanan terutama perikanan tangkap di Buleleng menunjukkan peningkatan, tercermin dari peningkatan produksi yang cukup pesat dari tahun 2012 sebesar 12,276 ton, 2013 sebesar 14,243 ton dan di tahun 2014 sebesar 17,711 ton dengan 27 jenis ikan yang tertangkap (Anonim, 2014). Potensi perairan kabupaten Buleleng, selain memiliki potensi perikanan tangkap juga mempunyai potensi perikanan budidaya. Kawasan laut yang dapat dimanfaatkan sebagai budidaya mencapai luas 1000 ha, dengan jenis budidaya sebagai berikut : 1) budidaya Kerapu dan Bandeng yang dapat seluas 500 ha dan pada tahun 2012 pemanfaatan baru mencapai 3,50 ha $(0,70 \%)$ dengan hasil produksi sebesar 56,70 ton, dan sisa peluang investasi seluas 496,5 ha $(99,3 \%)$ (Anonim, 2013).

\section{Kualitas Perairan}

Secara umum nilai rata-rata parameter kualitas air di pesisir Buleleng masih layak atau mendukung untuk dilakukannya kegiatan mina wisata bahari. Hal ini dapat dilihat dari nilai yang didapatkan masih berada pada kisaran baku mutu air untuk wisata bahari yang ditetapkan oleh Kepmen Negara LH No. 51 tahun 2004. Kondisi kualitas air pada perairan pesisir Buleleng dapat dilihat pada Tabel 2.

Dari 6 parameter yang diuji (Tabel 2), tidak ada parameter yang melebihi atau melewati ambang batas baku mutu air laut untuk wisata bahari sesuai Kepmen Negara LH No. 51 tahun 2004. Namun kondisi yang perlu mendapat perhatian adalah di stasiun II, di mana kondisi periran lebih rendah dari stasiun lainnya. Kondisi kualitas perairan stasiun II tidak terlepas dari keadaan pesisirnya yang banyak terdapat pemukiman penduduk dan letaknya yang cukup dekat dengan pantai, sehingga limbah antropogenik dapat masuk ke perairan.

Kondisi kualitas perairan pesisir Buleleng yang secara umum masih tergolong baik, sudah tentu akan berpengaruh terhadap biota dan lingkungan sekitar-

Tabel 2. Kondisi kualitas perairan lokasi penelitian.

\begin{tabular}{lllllll}
\hline Stasiun & Temperatur $\left({ }^{\circ} \mathrm{C}\right)$ & Turbiditas $(\mathrm{NTU})$ & $\mathrm{pH}$ & Salinitas $(\% / 00)$ & $\mathrm{DO}(\mathrm{mg} / \mathrm{L})$ & $\mathrm{NH}_{3}(\mathrm{mg} / \mathrm{L})$ \\
\hline 1 & 28 & 0,055 & 7,6 & 31,4 & 7,87 & 0 \\
2 & 29 & 2,033 & 7,4 & 30,0 & 6,88 & 0 \\
3 & 28 & 0,030 & 7,8 & 31,8 & 8,05 & 0 \\
\hline
\end{tabular}

Sumber : Hasil pengukuran. 
nya termasuk di dalamnya adalah terumbu karang. Semua karang hermatipik membutuhkan cahaya yang cukup untuk kegiatan fotosintesis. Karang hermatipik adalah karang yang mampu menghasilkan terumbu. Karang hermatipik hidup bersimbiosis dengan alga (zooxanthellae) yang melakukan proses fotosintesis. Penetrasi cahaya matahari (illumination) sangat menentukan kedalaman habitat terumbu karang (Sammarco dkk. 2014)

Pertumbuhan karang ditinjau dari penetrasi cahaya yang biasanya rendah diakibatkan oleh jumlah partikel-partikel tersuspensi dari air sungai yang masuk ke laut (Harris dkk. 2013). Kekeruhan dan sedimentasi yang terjadi di pesisir Buleleng masih dalam batas yang dapat ditoleransi oleh organisme karang, namun demikian sedimentasi dan kekeruhan sangat berpotensi terjadi karena dekat dengan daratan, sehingga merupakan ancaman bagi terumbu karang.

Kekeruhan air laut dan sedimentasi dapat memberikan dampak negatif terhadap pertumbuhan karang dan morfologi karang (McManus dkk. 2000). Kekeruhan yang disebabkan nutrien yang kaya di perairan akan membahayakan karang dan bahkan mampu membunuh terumbu karang, salah satunya adalah akibat kompetisi antara karang dengan alga yang sudah sangat luas terjadi di sejumlah terumbu karang dengan melibatkan sejumlah interaksi. Karang yang bertahan di bawah kondisi stres berat

dapat menurunkan pertumbuhan dan potensi reproduksinya (Abelson dan Yehiam, 2002).

\section{Kondisi Sosial Budaya Masyarakat Kawasan Pesisir Buleleng}

Secara sosial budaya masyarakat pesisir Buleleng telah mengenal dan terbiasa dalam hal pariwisata terutama aktivitas wisata bahari, maka pengembangan kegiatan mina wisata bahari dapat diterima oleh masyarakat terlebih aktivitas ini merupakan pengembangan aktivitas wisata bahari yang telah ada atau telah eksis sebelumnya seperti diving dan snorkeling sehingga dapat menjadi alternatif aktivitas wisata serta dapat menjadi jembatan antara masyarakat yang bermata pencaharian dari sektor pariwisata dengan masyarakat yang berprofesi sebagai nelayan, karena konsep mina wisata berbasiskan perikanan, sehingga ada sinergi di dalam pemanfaatan sumberdaya untuk mewujudkan peningkatan kesejahteraan sosial masyarakat pesisir. Erlend dkk. (2011) menyebutkan bahwa wisata perikanan dapat memberikan stimulus positif bagi masyarakat lokal dari segi ekonomi.

\section{Analisis Dampak Kegiatan Wisata Bahari Terhadap Masyarakat}

Suatu kegiatan apapun yang memanfaatkan alam atau lingkungan, pasti memiliki dampak. Untuk menganalisis dampak tersebut digunakan analisis melalui penggunan matriks IFE (Tabel 3) dan EFE (Tabel 4).

Tabel 3. Hasil pengolahan matriks IFE.

\begin{tabular}{lccc}
\hline \multicolumn{1}{c}{ Faktor-faktor strategi internal } & Bobot & Rating & Skor \\
\hline Kekuatan & & & \\
1. Potensi biofisik. & 0,212 & 4 & 0,848 \\
2. Dukungan dari masyarakat. & 0,198 & 4 & 0,792 \\
3. Potensi tenaga kerja. & 0,089 & 4 & 0,356 \\
Kelemahan & & & \\
1. Keterampilan yang masih rendah. & 0,113 & 2 & 0,226 \\
2. Pendidikan yang masih rendah. & 0,114 & 2 & 0,228 \\
3. Kurangnya modal usaha. & 0,274 & 1 & 0,274 \\
\hline$\quad$ Total & 1,000 & - & 2,724 \\
\hline
\end{tabular}

Nilai rating: 1: kelemahan mayor, 2: kelemahan minor, 3: kekuatan minor, 4: kekuatan mayor.

Tabel 4. Hasil pengolahan matriks EFE.

\begin{tabular}{|c|c|c|c|}
\hline Faktor-faktor strategi eksternal & Bobot & Rating & Skor \\
\hline \multicolumn{4}{|l|}{ Peluang } \\
\hline 1. Adanya kesempatan kerja. & 0,086 & 3 & 0,258 \\
\hline 2. Adanya kesempatan berusaha. & 0,132 & 4 & 0,528 \\
\hline 3. Diversifikasi usaha. & 0,142 & 4 & 0,568 \\
\hline 4. Bertambahnya wawasan dan pengetahuan masyarakat. & 0,140 & 3 & 0,420 \\
\hline \multicolumn{4}{|l|}{ Ancaman } \\
\hline 1. Kerusakan sumberdaya. & 0,088 & 3 & 0,264 \\
\hline 2. Tumpang tindih kewenangan. & 0,183 & 4 & 0,732 \\
\hline 3. Pencemaran lingkungan. & 0,144 & 2 & 0,288 \\
\hline 4. Perubahan pola hidup. & 0,085 & 2 & 0,170 \\
\hline Total & 1,000 & - & 3,228 \\
\hline
\end{tabular}

Nilai rating: 1 = respon masyarakat kurang, 2 = respon rata-rata, 3 = respon bagus, $4=$ respon masyarakat sangat bagus 
Tabel 5. Rencana model pengembangan mina wisata.

\begin{tabular}{|c|c|c|}
\hline No & Wilayah & Aktivitas \\
\hline & & 1. Mina wisata perikanan budidaya (ikan hias dan karang) \\
\hline \multirow[t]{2}{*}{1} & Pesisir Buleleng Timur & 2. Mina wisata perikanan tangkap (pemancingan, spearfishing adventures) \\
\hline & & 3. Reef walking \\
\hline \multirow{2}{*}{2} & Pesisir Buleleno Tengah & 1. Mina wisata perikanan budidaya (rumput laut) \\
\hline & 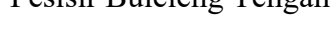 & 2. Mina wisata perikanan tangkap (pemancingan, spearfishing adventures) \\
\hline \multirow{3}{*}{3} & Pesisir Buleleng Barat & $\begin{array}{l}\text { 1. Mina wisata perikanan budidaya (rumput laut, Bandeng, Kerapu, Mutiara, } \\
\text { ikan hias, karang) }\end{array}$ \\
\hline & & 2. Mina wisata perikanan tangkap (pemancingan, spearfishing adventures) \\
\hline & & 3. Reef walking \\
\hline
\end{tabular}

Hasil perhitungan matriks IFE, berdasarkan nilai rating maka diperoleh faktor internal yang menjadi kekuatan utama (mayor) dari masyarakat yaitu potensi biofisik dengan skor nilai 0,848 , dukungan dari masyarakat dengan skor nilai 0,792 , dan potensi tenaga kerja dengan skor nilai 0,356. Kekuatan minor dari masyarakat tidak ada. Untuk faktor internal yang menjadi kelemahan terpenting bagi masyarakat dalam pengembangan wisata bahari yaitu kurangnya modal usaha dengan skor nilai 0,274 .

Untuk hasil perhitungan matriks EFE, faktor eksternal yang menjadi peluang terpenting bagi masyarakat dalam pengembangan mina wisata bahari yaitu diversifikasi usaha dengan skor nilai 0,568 , dan adanya kesempatan berusaha dengan skor nilai 0,528. Untuk faktor ekternal yang dapat menjadi ancaman bagi masyarakat dan dapat mempengaruhi pengembangan wisata bahari berupa tumpang tindih kewenangan dengan skor nilai 0,732.

Dilihat dari hasil perhitungan matriks IFE dan EFE tersebut, dapat diketahui bahwa masyarakat menginginkan adanya pengembangan wisata bahari di tempat tinggal mereka. Untuk itu masyarakat harus diberi kesempatan ikut serta atau dilibatkan dalam pengelolaan, terlebih untuk konsep pengelolaan pulau Menjangan yang berkelanjutan yang menjadi alternatif strategi pengelolaan. Dengan melibatkan masyarakat dalam pengelolaan, selain dapat menjamin kelestarian sumberdaya kelautan juga dapat menjamin kelangsungan dan kesejahteraan hidup masyarakat sekitarnya.

Melibatkan masyarakat dalam pengelolaan akan mendapatkan keuntungan ganda. Pertama mereka memperoleh pendapatan keluarga melalui pemanfaatan sumberdaya untuk pariwisata, kedua mereka pasti menjaga kelestarian dan keberlangsungan dari sumberdaya yang dimanfaatkan karena jika sumberdaya rusak maka akan berdampak pada penurunan penghasilan mereka sehingga secara tidak langsung mereka akan menjaga keberadaan sumberdaya tersebut agar tetap mendapatkan penghasilan untuk keperluan keluarga mereka.
Nijikuluw (2002), menyatakan bahwa pelibatan masyarat lokal dalam pengelolaan meberikan manfaat positif yaitu mampu mendorong pemerataan (equity) dalam pengelolaan sumberdaya perikanan, mampu merefleksikan kebutuhan masyarakat lokal yang spesifik, responsif dan adaptif terhadap variasi kondisi sosial dan lingkungan lokal dan masyarakat lokal termotivasi untuk mengelola sumberdaya secara berkelanjutan.

\section{Tingkat Kesesuaian, Daya Dukung Kawasan dan Rencana Model Mina Wisata Bahari}

Untuk tingkat kesesuaian dan daya dukung kawasan dalam menunjang kegiatan mina wisata bahari di kawasan Pesisir Buleleng dapat dikatakan sesuai berdasarkan hasil perhitungan menurut indeks kesesuaian kawasan untuk mina wisata bahari dengan daya dukung yang terkategori tinggi, sedangkan rencana bentuk model mina wisata yang nantinya akan dikembangkan dapat dilihat pada Tabel 5 .

\section{KESIMPULAN}

Dari hasil dan pembahasan yang diperoleh maka dapat disimpulan bahwa pesisir Kabupaten Buleleng apabila dilihat dari kondisi dan potensi sumberdaya alamnya masih mampu untuk mendukung aktivitas mina wisata bahari dengan tingkat kesesuaian dan daya dukung kawasan untuk aktivitas mina wisata bahari terkategori sesuai, sehingga pengembangan mina wisata di pesisir Buleleng dapat dilakukan dengan pertimbangan rencana bentuk model mina wisata yang dikembangkan antara lain mina wisata perikanan budidaya (rumput laut, Bandeng, Kerapu, Mutiara, ikan hias, karang), mina wisata perikanan tangkap (pemancingan, spearfishing adventures) dan reef walking.

\section{UCAPAN TERIMAKASIH}

Penulis menyampaikan ucapan terima kasih kepada pihak DP2M Dikti atas kepercayaan yang diberikan kepada penulis untuk mengerjakan 
penelitian dengan SPK nomor: 54/UN48.14/PL/ 2014 Tanggal 6 Maret 2014.

\section{DAFTAR PUSTAKA}

Abelson, A., dan Yehiam, S., 2002. Comparison of The Development of Coral and Fish Communities on Rock Aggregated Artificial Reefs In Eilat Red Sea. ICES Journal of Marine Science, 59:122-126.

Anonim, 2001. Peta Potensi Sumber Daya Alam Wilayah Pesisir dan Laut Kabupaten Buleleng Provinsi Bali, Buleleng.

Anonim, 2013. Buleleng Dalam Angka. Badan Pusat Statistik Kabupaten Buleleng, Buleleng 250 hal.

Anonim, 2014. Produksi Penangkapan Perikanan Laut Menurut Jenis Ikan di Kabupaten Buleleng. Dinas Kelautan dan Perikanan Kabupaten Buleleng, Buleleng.

Bachtiar, 2001. Pengelolaan Terumbu Karang. Pusat Kajian Kelautan Universitas Mataram. Mataram, 74 hal.

Chateau, O., dan Wantiez, L., 2009. Movement Patterns of Four Coral Reef Fish Species in A Fragmented Habitat in New Caledonia: Implications for The Design of Marine Protected Area Networks. ICES Journal of Marine Science, 66(1):50-55.

Darmawan, A., dan Miftahul, A., 2012. Pengembangan Minawisata Pulau-Pulau Kecil Untuk Mendukung Implementasi Blue Economy. KONAS VIII Pengelolaan Pesisir, Laut dan Pulau-Pulau Kecil. Mataram.

Davis, D., dan Tisdell, C., 1995. Recreational SCUBA Diving and Carrying Capacity in Marine Protected Areas. Ocean and Coastal Management, 26:19-40.

Davis, D., dan Tisdell, C., 1996. Economic Managementof Recreational SCUBA Diving and The Environment. Journal of Environmental Management, 48:229-248.

deVantier, L., dan Turak, E., 2004. Managing Marine Tourism in Bunaken National Park and Adjacent Waters. Technical Report was preprared by The Natural Resources Management (NRM III) Program's Protected Areas and Agriculture Team. Manado.

Dexter, W., Ronald, D., dan Maria, V., 2014. Community Based, Low-Tech Method of Restoring A Lost Thicket of Acropora Corals. ICES Journal of Marine Science, 71(7):18661875.

English, S., Wilkinson, C., dan Baker, V., 1994. Survey Manual for Tropical Marine Resource.
Australian Institute of Marine Science. Townsville.

Erlend, M., Jakob, G., Guillaume, L., Eirik, M., Esben, M., Hakan, T., dan Volstad, J., 2011. Effects of Fishing Tourism in a Coastal Municipality: a Case Study from Risor Norway. Ecology and Society, 16(3):11-21.

Ferter, K., Weltersbach, M.S., Strehlow, H.V., Volstad, J.H., Alo's, J., Arlinghaus, R., Armstrong, M., Dorow, M., de Graaf, M., van der Hammen, T., Hyder, K., Levrel, H., Paulrud, A., Radtke, K., Rocklin, D., Sparrevohn, C.R., dan Veiga, P., 2013. Unexpectedly High Catch-And-Release Rates In European Marine Recreational Fisheries: Implications for Science and Management. ICES Journal of Marine Science, 70:13191329.

Harris, P, Bridge, T., Beaman, R., Webster, J., Nichol, S., dan Brooke, B., 2013. Submerged Banks in The Great Barrier Reef, Australia, Greatly Increase Available Coral Reef Habitat. ICES Journal of Marine Science, 70(2):284293.

Hutabarat, A., Yulianda, F., Fahrudin, A., Harteti, S., dan Kusharjani., 2009. Pengelolaan Pesisir dan Laut Secara Terpadu (Edisi I). Pusdiklat Kehutanan. Deptan. SECEN-KOREA International Coorperation Agency.

Kasnir, M., 2011. Analisis Aspek Ekologi Penatakelolaan Minawisata Bahari di Kepulauan Spermonde Kabupaten Pangkep Sulawesi Selatan. Jurnal Ilmu Kelautan, 16(2):61-69.

Martinez, S., dan Abelson, A., 2013. Coral Recruitment: The Critical Role of Early PostSettlement Survival. ICES Journal of Marine Science, 70(7):1294-1298.

McManus, J., Menez, L., Kesner-Reyes, L., Vergara, S., dan Ablan, M., 2000. Coral Reef Fishing and Coral-Algal Phase Shifts: Implications for Global Reef Status. ICES Journal of Marine Science, 57(3):572-578.

Nybakken, J.W. 1993. Marine Biology. An Ecological Approach. Third Edition. Harper Collins College Publishers. New York.

Nikijuluw, V., 2002. Rezim Pengelolaan Sumberdaya Perikanan. PT. Pustaka Cidesindo. Jakarta.

Sammarco, P,W., Lirette, A., Tung, Y,F., Boland, G.S., Genazzio, M., dan Sinclair, J., 2014. Coral Communities on Artificial Reefs In The Gulf of Mexico: Standing vs Toppled Oil Platforms. ICES Journal of Marine Science, 71(2):417426. 
Simon, F., Yeamduan, N., dan Daniel, P., 2004. Carrying Capacity in The Tourism Industry: A Case Study of Hengistbury Head. Tourism Management Journal, 25:275-283.

Strehlow, H,V., Schultz, N., Zimmermann, C., dan Hammer, C., 2012. Cod Catches Taken by The German Recreational Fishery In The Western Baltic Sea, 2005-2010: implications For Stock Assessment And Management. ICES Journal of Marine Science, 69:1769-1780.

Stone, R,P., Michele, M, dan John F,K., 2015. Assessing The Ecological Importance of Red Tree Coral Thickets in The Eastern Gulf of Alaska. ICES Journal of Marine Science, 72(3):900-915.

Volstad, J,H., Korsbrekke, K., Nedreaas, K,H., Nilsen, M., Nilsson, G,N., Pennington, M.,
Subbey, S., dan Wienerroither, R., 2011. Probability-Based Surveying Using SelfSampling to Estimate Catch and Effort In Norway's Coastal Tourist Fishery. ICES Journal of Marine Science, 68:1785-1791.

Yudasmara, A.G., 2010. Model Ekowisata Bahari di Pulau Menjangan Kawasan Taman Nasional Bali Barat. Disertasi. Institut Pertanian Bogor. Bogor.

Yudasmara, A.G., 2013. Pendekatan Sistem Dinamik dalam Pemodelan Pengelolaan Wisata Bahari di Kawasan Pesisir Kabupaten Buleleng. Laporan Penelitian Hibah Unggulan Perguruan Tinggi. Lembaga Penelitian, Universitas Pendidikan Ganesha. Singaraja. 